\title{
Distinct Composition and Assembly Processes of Bacterial Communities in a River From The Arid Area: Ecotypes or Habitat Types?
}

\section{Ran Qi}

China University of Geosciences

Nana Xue

Xinjiang Agricultural University

\section{Xiaobin Zhou}

University of Chinese Academy of Science

\section{Li Zhao}

Xinjiang Institute of Ecology and Geography, Chinese Academy of Sciences

Wen juan song ( $\nabla$ songwj@ms.xjb.ac.cn )

Xinjiang Institute of Ecology and Geography https://orcid.org/0000-0002-6443-6044

\section{Yuyi Yang}

University of Chinese Academy of Science

\section{Research Article}

Keywords: Ili River, Community structure, Dirichlet multinomial mixture, Neutral community model, Stochastic process, Ecotypes

Posted Date: August 10th, 2021

DOl: https://doi.org/10.21203/rs.3.rs-772586/v1

License: (9) This work is licensed under a Creative Commons Attribution 4.0 International License. Read Full License 


\section{Abstract}

The composition, function, and assembly mechanism of the bacterial community are the focus of microbial ecology. Unsupervised machine learning may be a better way to understand the characteristics of bacterial metacommunities compared to the empirical habitat types. In this study, the composition, function, and assembly mechanism of the bacterial community in the arid river were analyzed. Four ecotypes were recognized across the three habitats (biofilm, water, and sediment) by Dirichlet multinomial mixture method. The bacterial communities in water are more sensitive to human activities. Bacterial diversity and richness in water decreased as the intensity of human activities increased from the region of Water II to Water I. Significant differences in the composition and function profile of bacterial communities between water ecotypes were also observed, such as higher relative abundance in the taxonomic composition of Firmicutes and function of plastic degradation in Water I than those in Water II. Habitat filtering may play a more important role in the assembly of bacterial communities in the river biofilm, while stochastic processes dominated the assembly process of bacterial communities in water and sediment. In Water I, salinity and mean annual precipitation were the main drivers shaping the biogeography of taxonomic structure, while mean annual temperature, total organic carbon, and ammonium nitrogen were the main environmental factors influencing the taxonomic structure in the Water II. These results would provide conceptual frameworks about how to choose habitat types or ecotypes for the research of microbial communities among different niches in the aquatic environment.

\section{Introduction}

Bacterial communities play an important role in river ecosystems, such as the element cycle, degradation of organic matter. The perturbations to the river bacterial communities can affect the entire system, such as leading to algal blooms $[1,2]$ and black-odor waterbody $[3,4]$. Hence, understanding the composition, function, and assembly processes of bacterial communities in rivers is gaining more and more attention in the recent decade [5-7].

Many factors influenced the composition, function, and assembly processes of aquatic microbial communities, such as landscape and environmental factors. In the Yangtze River of China, the landscapes (mountain, foothill, basin, foothill-mountain, and plain) were an important driver shaping bacterial communities in both water and sediment [8]. $\mathrm{NH}_{4}{ }^{+} \mathrm{N}$ is found to be one of the key factors affecting the composition of river bacterial communities [3,9]. The relative importance of deterministic and stochastic processes was also analyzed to underline the assembly mechanism of bacterial communities in the aquatic environment $[8,10,11]$. The deterministic process is driven by contemporary environmental heterogeneity, while stochastic processes are influenced by communities variation $[12,13]$. Dispersal limitation of stochastic processes was found to shape the spatial patterns of anammox bacterial communities in river sediment [10]. Stochastic processes also drove the assembly mechanism of water microeukaryotic communities in a subtropical river [14]. However, deterministic environmental filtering played a more important role in shaping benthic bacterial communities, while stochastic processes play a greater role in the water column [15]. 
In the river catchments, most researchers investigated the composition, function, and assembly processes of bacterial communities based on habitat types (e.g., water, biofilm, or sediment) or landscapes within them $[8,10,15,16]$. In the River Thames, the assembly mechanism of bacterial community within habitat types including the free-living, particle-associated, biofilm, and sediment exhibited consistency [15]. A meta-analysis also confirmed that bacterial phyla showed similar patterns in the same habitat among different streams [17]. While, in the Bahe River, the bacterial communities in residential and industrial areas exhibited different assembly mechanisms [16]. In the Yangtze River, four groups were found within sediment habitats, proving the effect of dams on benthic bacterial communities [18]. These results indicated that habitat types were given priority to be considered, then followed by the landscape or other environmental conditions within the same habitat in most previous studies. However, should it be like this? In this study, the unsupervised partitioning of microbial metacommunities was applied among different habitat types not within the same compartment. We proposed that more ecotypes (or metacommunity types) could be found than habitat types, which would challenge the empirical analysis method based on habitat types. We addressed this issue by testing a range of interacting habitats (water, sediment and biofilm) at sites across a river catchment.

In this study, the bacterial communities of three major niches (water, sediment, and biofilm) in the lli River were firstly partitioned via the unsupervised Dirichlet multinomial mixture (DMM) method, and the underlined assembly mechanism and co-occurrence patterns of bacterial communities were determined. Water, sediment, and biofilm samples from the mainstream of the lli River and its three tributaries were collected to study the responses of bacterial communities in a wide range of habitats under different environmental conditions. These results would provide conceptual frameworks about how to choose habitat types or ecotypes for the research of microbial communities among different niches in the aquatic environment.

\section{Materials And Methods}

\section{Study site and samples collection}

Ili River originating from Tianshan Mountain is an important water resource in arid Central Asia. The climate in this region is temperate continental and alpine with an average annual precipitation of 200 to $800 \mathrm{~mm}$ [19]. The lli River valley $\left(80^{\circ} 09^{\prime} \mathrm{E}-84^{\circ} 56^{\prime} \mathrm{E}, 42^{\circ} 14^{\prime} \mathrm{N}-44^{\circ} 50^{\prime} \mathrm{N}\right)$ is in the hinterland of the Eurasian continent with an altitude ranging from 538 to $5859 \mathrm{~m}$ [20]. The Kunes River, Tekes River, and Kash River are major tributaries of the lli River. In this study, six, seven, six, nine sampling sites were set in Kunes River, Tekes River, Kash River, and the mainstream of lli River, respectively (Supplementary materials, Fig. S1). Each sample was a mixture of at least three subsamples that were randomly collected within an area of $5 \mathrm{~m}^{2}$. For water samples, $1 \mathrm{~L}$ of surface water was finally obtained in an autoclaved polypropylene bottle, filtered via $0.22 \mu \mathrm{m}$ membrane within $12 \mathrm{~h}$. The filtered membrane, biofilm, and sediment samples were sealed in sterilized tubes and stored at $-20^{\circ} \mathrm{C}$ for DNA extraction. The mean annual temperature (MAT) and precipitation (MAP) of sampling sites were obtained from Resource and Environment Science and Data Center (https://www.resdc.cn/). The pH, salinity (salt), total organic carbon (TOC) and nitrogen 
(TN), available nitrogen (AN) and phosphrus (AP) nitrate (NN) and ammonium nitrogen (ANM) in water or sediment were determined according to the environmental monitoring method standards of Ministry of Ecology and Environment of the People's Publica of China.

\section{Full-length 16S rRNA sequencing and data processing}

The filtered membrane, biofilm, and sediment samples were used to extract DNA via PowerSoil DNA Isolation Kit (MO BIO) according to the manufacturer's protocols. The composition of bacterial communities in water, sediment, and biofilm was detected by $16 \mathrm{~S}$ rRNA full-length sequencing method, which is offered by PacBio single-molecule, real-time (SMRT) technology. Raw paired-end reads were merged using FLASH v1.2.11 [21] and filtered by Trimmomatic v0.33 [22] and UCHIME v8.1 [23]. Then, the obtained clean tags were clustered into OTU by USEARCH version 10.0 at $97 \%$ similarity levels [24]. The OTUs with relative abundance less than $0.005 \%$ were removed [25]. After that, the taxonomy was annotated using RDP Classifier against the Silva (Release132, http://www.arb-silva.de) database with a confidence threshold of 0.8 [26]. The predicated function profile of bacterial communities was analyzed using FAPROTAX [27] on the platform BMKCloud (www.biocloud.net).

\section{Partitioning of bacterial communities}

Dirichlet multinomial mixture (DMM) was a robust method for partitioning bacterial communities [18]. In this study, the online R code of DMM (https://microbiome.github.io/tutorials/DMM.html) was used to partition bacterial metacommunities in water, sediment, and biofilm with rarity threshold of OTUs from 0 to $0.5 \%$. The principal coordinate analysis (PCoA) and difference in Bray-Curtis distance of bacterial metacommunities based on OTUs within the water, sediment, and biofilm samples were applied to verify the confidence of the DMM result.

\section{Diversity and model fitting of bacterial metacommunities}

Chao1 and Shannon index of bacterial communities of each sample were calculated to assess the richness and diversity of bacterial communities. Kruskal-Wallis test was applied to compare the difference of Chao1 and Shannon index among sample groups. The above analysis was carried out using a "microeco" package of R software [28]. The differences in taxonomic and functional composition of bacterial communities were detected via the Turkey test. The correlations between environmental parameters and taxonomic (OTU level) and the functional composition of bacterial communities across different habitats or ecotypes were analyzed by Mantel test via R software. A neutral community model (NCM) was applied to distinguish the contribution of stochastic processes to bacterial community assembly by analyzing the relationship between the occurrence frequency of taxa and their relative abundance $[27,29,30]$. In the model, $\mathrm{R}^{2}$ and " $\mathrm{m}$ " represent the goodness of fit and the migration rate, respectively $[16,30]$.

\section{Results}




\section{Statistics of sequencing results and partition of bacterial metacommunities}

The 69 samples including water, sediment, and biofilms were sequenced by PacBio and identified by Barcode. A total of 882, 211 circular consensus sequencing (CCS) sequences were obtained. Each sample was produced at least 10, 129 CCS sequences, with an average of 12, 786 CCS sequences. After rarefaction, the sequences were clustered into 1434 OTUs, among which 1350, 1285, and 1078 OTUs were identified from water, sediment, and biofilm, respectively. The bacterial metacommunities were partitioned at the OTU level with different rarity thresholds by Dirichlet multinomial mixture (DMM) methods (Fig. 1a). Four optimal clusters were finally obtained, indicating that the samples from three habitats (water, sediment, and biofilm) could be automatically classified into four different ecotypes of bacterial communities acclimated to the environment of the lli River. Cluster I (Sediment) included 26 sediment samples and two water samples. Cluster II (Biofilm) included all biofilm samples and one sediment sample. Cluster III (Water I) was composed of most water samples from Kunes River and mainstream of Ili River, and one sediment sample. All water samples from Tekes River and Kashi river, and one sample from Kunes River constituted Cluster IV (Water II). Considering the consistency of sample habitat, the two water samples, one and one sediment sample from Cluster I, Cluster II and Cluster III were removed in the following study. The PCOA (Fig. 1b) and the differences in Bray-Curtis within groups (Fig. 1d) also confirmed the confidential clusters. These results also indicated that the water samples could be mainly divided into two clusters. The average population and gross domestic product (GDP) in the main region (Tekes river and Kashi river basin) of Water II were 21.34 people per $\mathrm{km}^{2}$ and 472, $500 \mathrm{RMB}$ per $\mathrm{km}^{2}$, which were lower than those in the main region of Water I (48.00 people per $\mathrm{km}^{2}$ and $1,025,000$ RMB per $\mathrm{km}^{2}$ ). Grassland and woodland were the dominant landscape in the main region of Water II. The main towns (Xinyuan County, Gongliu County, Yining City) in the lli River Valley are located along the Kunes River and mainstream of Ili River (Water I). Therefore, bacterial communities in water are more sensitive to human activities, compared to sediment and biofilm under the same background of climate and geography.

\section{Species diversity and abundance distribution at four optimal clusters}

From the results of the Kruskal-Wallis test, there were no statistical differences in the Chao1 richness and Shannon index between the metacommunities from biofilm and Water I (Fig. 2a). Sediment had the highest Chao1 richness $(601 \pm 116)$ and Shannon index $(4.87 \pm 0.45)$, which were higher than those in Water II ( $471 \pm 115$ and $4.11 \pm 0.31$ ), biofilm ( $305 \pm 126$ and $3.05 \pm 0.96)$, and Water I ( $341 \pm 135$ and $2.92 \pm 0.82$ ) (Fig. 2a and 2b). These results indicated that bacterial diversity and richness in water decreased as the intensity of human activities increased. However, there was no difference in Chao1 and Shannon index in bacterial communities between water and sediment according to the common conditional analysis based on habitat types (Fig. 2c and 2d). The significant difference within water samples was also ignored by habitat type.

At the phylum level, the most abundant and common taxa across all the four clusters were Proteobacteria (Fig. 1c). Fig. 3 showed the differences in relative abundance of the top 12 phyla in Water I, Water II, 
biofilm, and sediment samples. The average proportion of Proteobacteria in Water II (68.41\%) and biofilm (65.83\%), were significantly higher than those in sediment (50.97\%) and Water I (38.80\%). Firmicutes had the highest percentage in Water I (44.17\%), followed by Water II (8.94\%), sediment (5.93\%), and biofilm (0.42\%). Significant higher proportions of Bacteroidota, Acidobacteriota, Panctomycetota, Desulfobacterota, Germmatimonadota, and unclassified bacteria were found in sediment. Biofilm had the highest percentage of Cyanobacteria (18.38\%), which were higher than those in Water I (5.52\%), Water II $(2.95 \%)$, and sediment $(0.20 \%)$. Actinobacteriota was observed in Water II with a relative abundance of $9.3 \%$, which was higher than those in Water I $(2.97 \%)$, sediment $(2.06 \%)$, and biofilm $(0.26 \%)$. That is also to say, Proteobacteria and Actinobacteriota had significantly higher relative abundance in Tekes River and Kashi River with less human activities than those in Kunes River and mainstream of lli River, while the relative abundance of Firmicutes was reversed. By habitat types, the neglect of significant differences within water samples led to different results in the relative abundance of bacterial communities. For example, no difference in the relative abundance of Proteobacteria between water and biofilm was found; and the significant difference in the relative abundance of Firmicutes within water samples was also ignored (Fig. S2). Therefore, these results further confirmed that ecotypes may be a better way to understand the characteristics of bacterial metacommunities than habitat types.

\section{The function profile of bacterial communities across the four optimal ecotypes}

Distinct function profile of bacterial communities predicated by FAPROTAX was found across different habitats or ecotypes in the Ili River (Fig. S3 and Fig.4). Chemoheterotrophy and aerobic chemoheterotrophy were the main functions. To further analyze the difference, the Turkey test was applied for function composition across the four different ecotypes (Fig. 4). The bacterial communities with functions of manganese oxidation, human pathogens nosocomia, human pathogens pneumonia, plastic degradation in the Water I had significantly higher relative abundance than those in Water II, sediment, and biofilm. Sediment had a significantly higher relative abundance in function of chemoheterotrophy and aerobic chemoheterotrophy than those in the Water I, Water II, and biofilm. Biofilm had a higher relative abundance of bacterial communities with phototrophy function than those of the other three ecotypes. Biofilm also had a higher relative abundance of photoautotrophy, cyanobacteria, and oxygenic photoautotrophy than those in Water II and sediment, but showed no significant difference compared with Water I. Compared with the habitat types (Fig. S3), the significant differences in function within the water samples were also neglected, such as the manganese oxidation, human pathogens nosocomia, human pathogens pneumonia, and plastic degradation.

\section{Bacterial communities across different ecotypes fitted to NCM}

The internal assembly mechanism of bacterial community across the four ecotypes was analyzed via NCM and shown in Fig. 5. Water (including Water I and Water II) and sediment showed higher goodnessof-fit to NCM $\left(R^{2}>0.5\right)$ than that of biofilm $\left(R^{2}=0.154\right)$. The migration rates of the four ecotypes were shown in the following order: biofilm $(0.0634)<$ sediment $(0.1525)<$ water I $(0.2514)<$ water II $(0.3415)$. These results indicated that an immigrant from metacommunities was less likely to randomly colonize in 
the saturated local communities in sediment and biofilm compared to water in the lli River. Meanwhile, the water I influenced by higher anthropogenic impacts also had a lower migration rate compared with water II with less human activities.

\section{Environmental factors influencing the composition and function of bacterial communities}

The relationship between environmental factors and community structure was important to understand the bacterial assembly process from the perspective of deterministic selection. Mantel's test (Fig. 6) showed that three, two, two and three environmental factors could influence the bacterial community structure at the OTU level for sediment, water, Water I, and Water II, respectively. While no tested environmental factors showed influence on the taxonomic structure of the biofilm. For bacterial communities in sediment, TOC, TN, and AP (available phosphorus) were the main drivers shaping the biogeography of taxonomic structure. In Water I with higher intensity of human activities, salinity and mean annual precipitation (MAP) were the main drivers, while mean annual temperature (MAT), TOC, and ammonium nitrogen (ANM) were the environmental factors influencing the taxonomic structure in the Water II with less human activities. If water was considered as a habitat, it was found that MAT and salinity were the main drivers influencing the water bacterial communities in the lli River.

\section{Discussion}

In this study, an unsupervised machine learning method instead of empirical experience was applied to identify the ecotypes of bacterial communities across the lli River. Four ecotypes were identified among samples from water, sediment, and biofilm. Water was more susceptible to be influenced by human activities and divided into two ecotypes. The difference in the taxonomic and functional composition and assembly processes of bacterial communities across the four ecotypes was found. Our study provided a conceptual framework about how to choose habitat types or ecotypes for the research of microbial communities among different niches in the aquatic environment.

\section{Distinct bacterial communities across the four ecotypes}

Bacterial communities in the same habitat could be divided into different ecotypes, which was firstly reported in the study of the human gut microbiome [31]. Dirichlet multinomial mixtures as a robust method have been widely applied in the pattern recognition of microbiome in the same habitat, such as aerobic composting sludge [32], soil [33], and sediment [18]. Bacterial phyla showed similar patterns in the same habitat among different streams [17], so fewer studies used the Dirichlet multinomial mixtures method to partition microbiome across different habitat types in river ecosystem. However, in this study, the microbiome across three habitats (e.g., sediment, biofilm, and water) was divided into four ecotypes via the unsupervised Dirichlet multinomial mixtures method. The microbiome of three niches (workplaces, high-touch areas, and environments) in healthcare-associated institutes in Taiwan was also divided into four ecotypes via Dirichlet multinomial mixtures [34]. Therefore, Dirichlet-multinomial mixtures could be a better choice to identify the ecotypes of bacterial communities in the environment, rather than just based on the habitat types. 
Human activities played much more important role in shaping bacterial communities in water than that in sediment and biofilm. The higher diversity and richness of bacterial communities in Water II with less human activities were higher than those in Water I with intense human disturbance. In temperate southern Africa, the Chao1 richness and diversity of bacterial communities in Kowie River with relatively higher urban land use efficiency were also lower than those observed in Kariega River with less human activities [35]. The PCOA (Fig. 1b) and the differences in Bray-Curtis within groups also indicated that distinct bacterial communities formed between Water I and Water II. In Songhua River, the water bacterial communities in areas with high population density also exhibited different compositions compared to those in sites with low population density [36].

Firmicutes were the main bacteria $(44.17 \%)$ at the phylum level in Water I with intense human interference, followed by Proteobacteria (38.80\%). While in Water II with fewer human activities, Proteobacteria (68.41\%) and Actinobacteriota (9.3\%) were the top two bacteria at the phylum level. In the surface water along the Three Gorge Reservoir, Firmicutes was also the most dominant phyla and correlated with the concentration of chemical oxygen demand [37]. Firmicutes played an important role in the degradation of organic matters, such as sugar cane [38] and potato starch processing wastewater [39]. More organic matter could be discharged into Water I due to the higher human population and intense agricultural activities compared to Water II with less human activities, which may lead to the domination of Firmicutes. The functions predicated by the bacterial communities also confirmed that Water I experienced more human disturbance than Water II. For example, Water I had a higher relative abundance of bacterial communities with functions of human pathogens nosocomia, human pathogens pneumonia, and plastic degradation.

Significant higher proportions of Bacteroidota, Acidobacteriota, Panctomycetota, Desulfobacterota, Germmatimonadota, and unclassified bacteria were found in sediment. Bacteroidota showed a high potential for degradation of lignocellulosic polymers [40]. Desulfobacterota is a sulfate-reducing bacteria and showed a preference for freshwater environments [41]. These results indicated that sediment played a more important role in the biogeochemical cycles of elements, such as carbon and sulfur.

Cyanobacteria were the main bacteria in biofilm from the lli River, which was also in the biofilm from French and New Zealand rivers [42, 43].

\section{Different assembly mechanisms of bacterial communities across the four ecotypes}

NCM has been widely used to assess the assembly mechanisms of bacterial communities in the aquatic environment, such as Yangtze River [8], and Tingjiang River [14]. In this study, we found that the bacterial communities on the biofilms were not well fitted to the NCM, indicating stochastic processes were not the key assembly mechanism of bacterial communities in this habitat. Meanwhile, the environmental factors tested in water also did not correlate with the taxonomic composition of bacterial communities on biofilm. These results indicated that habitat filtering may play a more important role in the assembly of bacterial communities in the river biofilm. For Phormidium (cyanobacteria) biofilms in French and New 
Zealand rivers, it was also observed that dispersal capacities of bacteria were not the key factor driving the bacterial community [42].

Community composition of bacterial communities in Water I, Water II, and sediment were fitted to NCM with $R^{2}$ values between 0.516 and 0.563 , indicating a strong effect of dispersal limitation on the assembly of bacterial communities in water and sediment. Stochastic processes including dispersal limitation were the main driving ecological processes shaping the bacterial communities in the sediment from subtropical mangroves [29], and microeukaryotic community assembly in water from the subtropical river [14]. Two or three environmental factors were found to exert influence on the taxonomic composition of bacterial communities in Water I, Water II, and sediment. These results indicated that deterministic processes also played a partial role in shaping the bacterial communities in the water and sediment. Among the identifiable deterministic factors, TOC showed a significant influence in shaping the bacterial community structure of both sediment and water II. In previous studies, TOC was also found to be an important driver of bacterial communities in the Danube floodplain [44] and temperate lakes [45].

Salinity was the most important factor driving the bacterial community in Water I with intense human activities. Salinity was found to be the main driver shaping bacterial community structure in the inland freshwater lakes [46] and wetlands [47]. The Water I region is the main irrigation area of the lli River. Salinity is a threat to agricultural productivity and sustainability in the irrigation area of the lli River [48, 49], among which input of available phosphorus, alkaline nitrogen, available potassium was the important factor [49]. For the Water II region with less human activities and covered mainly by forest and grassland, MAT was the main driver shaping the bacterial communities in Water II. Water temperature was found to be the primary factor driving the bacterial community structure in the Yangtze River [8]. MAT was also found to mediate the assembly of the rare sub-communities in agricultural ecosystems of China from south to north [50]. If the habitat type was used for water together, the factors influencing the bacterial community assembly were MAT and salinity, and the difference in bacterial assembly mechanism within the water could be neglected.

\section{Conclusions}

In this study, distinct composition, function, and assembly mechanisms of bacterial communities were observed among different ecotypes partitioned by unsupervised machine learning. The Water I with higher intensity of human activities had a higher relative abundance of Firmicutes, while Proteobacteria and Actinobacteriota had significantly higher relative abundance in Water II with less human activities. Different driving factors for the bacterial community structure between the two water ecotypes were also found. These results indicated that unsupervised machine learning was a better way to understand the characteristics of bacterial metacommunities in the aquatic environment.

\section{Declarations}

Funding 
This work was supported by the National Natural Science Foundation of China [grant number 41673127] and grants from the Youth Innovation Promotion Association of the Chinese Academy of Sciences [grant number Y201976 and 2017478].

\section{Conflicts of interest/Competing interests}

None

\section{Availability of data and material}

All the raw data sets are publicly available in the Sequence Read Archive (SRA) of the National Center for Biotechnology Information (NCBI) under project accession no. PRJNA733708.

\section{Authors' contributions}

W.S. and R.Q. conceived and designed the study, W.S., N.X., and R.Q collected the samples and data; Y.Y. and W.S. performed the analysis; W.S., X.Z., and L.Z. wrote and revised the manuscript.

\section{Ethics approval}

Not applicable

\section{Consent to participate}

Not applicable

\section{Consent for publication}

All authors agreed to publish this manuscript.

\section{References}

1. Berry MA, Davis TW, Cory RM, Duhaime MB, Johengen TH, Kling GW, Marino JA, Den Uyl PA, Gossiaux D, Dick GJ, Denef VJ (2017) Cyanobacterial harmful algal blooms are a biological disturbance to Western Lake Erie bacterial communities. Environ Microbiol 19:1149-1162. doi:https://doi.org/10.1111/1462-2920.13640

2. Eiler A, Bertilsson S (2004) Composition of freshwater bacterial communities associated with cyanobacterial blooms in four Swedish lakes. Environ Microbiol 6:1228-1243. doi:https://doi.org/10.1111/j.1462-2920.2004.00657.x

3. Zhang W, Lei M, Li Y, Wang P, Wang C, Gao Y, Wu H, Xu C, Niu L, Wang L, Zhang H (2019) Determination of vertical and horizontal assemblage drivers of bacterial community in a heavily polluted urban river. Water Res 161:98-107. doi:https://doi.org/10.1016/j.watres.2019.05.107

4. Cai W, Li Y, Shen Y, Wang C, Wang P, Wang L, Niu L, Zhang W (2019) Vertical distribution and assemblages of microbial communities and their potential effects on sulfur metabolism in a black- 
odor urban river. J Environ Manag 235:368-376. doi:https://doi.org/10.1016/j.jenvman.2019.01.078

5. Lindström ES, Langenheder S (2012) Local and regional factors influencing bacterial community assembly. Environ Microbiol Rep 4:1-9. doi:https://doi.org/10.1111/j.1758-2229.2011.00257.x

6. Paudel Adhikari N, Liu Y, Liu K, Zhang F, Adhikari S, Chen Y, Liu X (2019) Bacterial community composition and diversity in Koshi River, the largest river of Nepal. Ecol Indic 104:501-511. doi:https://doi.org/10.1016/j.ecolind.2019.05.009

7. Read DS, Gweon HS, Bowes MJ, Newbold LK, Field D, Bailey MJ, Griffiths RI (2015) Catchment-scale biogeography of riverine bacterioplankton. The ISME J 9:516-526. doi:10.1038/ismej.2014.166

8. Liu T, Zhang AN, Wang J, Liu S, Jiang X, Dang C, Ma T, Liu S, Chen Q, Xie S, Zhang T, Ni J (2018) Integrated biogeography of planktonic and sedimentary bacterial communities in the Yangtze River. Microbiome 6:16. doi:10.1186/s40168-017-0388-x

9. Zhang L, Zhong M, Li X, Lu W, Li J (2020) River bacterial community structure and co-occurrence patterns under the influence of different domestic sewage types. J Environ Manag 266:110590. doi:https://doi.org/10.1016/j.jenvman.2020.110590

10. Chen L, Liu S, Chen Q, Zhu G, Wu X, Wang J, Li X, Hou L, Ni J (2020) Dispersal limitation drives biogeographical patterns of anammox bacterial communities across the Yangtze River. Appl Microbiol Biotechnol 104:5535-5546. doi:10.1007/s00253-020-10511-4

11. Wang J, Shen J, Wu Y, Tu C, Soininen J, Stegen JC, He J, Liu X, Zhang L, Zhang E (2013) Phylogenetic beta diversity in bacterial assemblages across ecosystems: deterministic versus stochastic processes. The ISME J 7:1310-1321. doi:10.1038/ismej.2013.30

12. Chase JM, Myers JA (2011) Disentangling the importance of ecological niches from stochastic processes across scales. Philos Trans R Soc Lond B Biol Sci 366:2351-2363. doi:10.1098/rstb.2011.0063 doi

13. Leibold MA, Holyoak M, Mouquet N, Amarasekare P, Chase JM, Hoopes MF, Holt RD, Shurin JB, Law R, Tilman D, Loreau M, Gonzalez A (2004) The metacommunity concept: a framework for multi-scale community ecology. Ecol Lett 7:601-613. doi:https://doi.org/10.1111/j.1461-0248.2004.00608.x

14. Chen W, Ren K, Isabwe A, Chen H, Liu M, Yang J (2019) Stochastic processes shape microeukaryotic community assembly in a subtropical river across wet and dry seasons. Microbiome 7:138. doi:10.1186/s40168-019-0749-8

15. Gweon HS, Bowes MJ, Moorhouse HL, Oliver AE, Bailey MJ, Acreman MC, Read DS (2021) Contrasting community assembly processes structure lotic bacteria metacommunities along the river continuum. Environ Microbiol 23:484-498. doi:https://doi.org/10.1111/1462-2920.15337

16. Wang L, Han M, Li X, Yu B, Wang H, Ginawi A, Ning K, Yan Y (2021) Mechanisms of niche-neutrality balancing can drive the assembling of microbial community. Mol Ecol 30:1492-1504. doi:https://doi.org/10.1111/mec.15825

17. Zeglin LH (2015) Stream microbial diversity in response to environmental changes: review and synthesis of existing research. Front Microbiol 6:454 
18. Gao Y, Zhang W, Li Y, Wu H, Yang N, Hui C (2021) Dams shift microbial community assembly and imprint nitrogen transformation along the Yangtze River. Water Res 189:116579. doi:https://doi.org/10.1016/j.watres.2020.116579

19. Liu X, Li L, Qi Z, Han J, Zhu Y (2017) Land-use impacts on profile distribution of labile and recalcitrant carbon in the lli River Valley, northwest China. Sci Total Environ 586:1038-1045. doi:https://doi.org/10.1016/j.scitotenv.2017.02.087

20. Li C, Wang R, Xu J, Luo Y, Tan ML, Jiang Y (2018) Analysis of meteorological dryness/wetness features for spring wheat production in the lli River basin, China. Int J Biometeorol 62:2197-2204. doi:10.1007/s00484-018-1623-2

21. Magoč T, Salzberg SL (2011) FLASH: fast length adjustment of short reads to improve genome assemblies. Bioinformatics 27:2957-2963. doi:10.1093/bioinformatics/btr507

22. Bolger AM, Lohse M, Usadel B (2014) Trimmomatic: a flexible trimmer for Illumina sequence data. Bioinformatics 30:2114-2120. doi:10.1093/bioinformatics/btu170

23. Edgar RC, Haas BJ, Clemente JC, Quince C, Knight R (2011) UCHIME improves sensitivity and speed of chimera detection. Bioinformatics 27:2194-2200. doi:10.1093/bioinformatics/btr381

24. Edgar RC (2013) UPARSE: highly accurate OTU sequences from microbial amplicon reads. Nat Methods 10:996-998. doi:10.1038/nmeth.2604

25. Bokulich NA, Subramanian S, Faith JJ, Gevers D, Gordon JI, Knight R, Mills DA, Caporaso JG (2013) Quality-filtering vastly improves diversity estimates from Illumina amplicon sequencing. Nat Methods 10:57-59. doi:10.1038/nmeth.2276

26. Quast C, Pruesse E, Yilmaz P, Gerken J, Schweer T, Yarza P, Peplies J, Glöckner FO (2013) The SILVA ribosomal RNA gene database project: improved data processing and web-based tools. Nucleic Acids Res 41:D590-D596. doi:10.1093/nar/gks1219

27. Louca S, Parfrey LW, Doebeli M (2016) Decoupling function and taxonomy in the global ocean microbiome. Science 353:1272. doi:10.1126/science.aaf4507

28. Liu C, Cui Y, Li X, Yao M (2021) microeco: an R package for data mining in microbial community ecology. FEMS Microbiol Ecol 97. doi:10.1093/femsec/fiaa255

29. Chen W, Wen D (2021) Archaeal and bacterial communities assembly and co-occurrence networks in subtropical mangrove sediments under Spartina alterniflora invasion. Environ Microbiome 16:10. doi:10.1186/s40793-021-00377-y

30. Sloan WT, Lunn M, Woodcock S, Head IM, Nee S, Curtis TP (2006) Quantifying the roles of immigration and chance in shaping prokaryote community structure. Environ Microbiol 8:732-740. doi:https://doi.org/10.1111/j.1462-2920.2005.00956.x

31. Arumugam M, Raes J, Pelletier E, Le Paslier D, Yamada T, Mende DR, Fernandes GR, Tap J, Bruls T, Batto J-M, Bertalan M, Borruel N, Casellas F, Fernandez L, Gautier L, Hansen T, Hattori M, Hayashi T, Kleerebezem M, Kurokawa K, Leclerc M, Levenez F, Manichanh C, Nielsen HB, Nielsen T, Pons N, Poulain J, Qin J, Sicheritz-Ponten T, Tims S, Torrents D, Ugarte E, Zoetendal EG, Wang J, Guarner F, Pedersen O, de Vos WM, Brunak S, Doré J, Antolín M, Artiguenave F, Blottiere HM, Almeida M, Brechot 
C, Cara C, Chervaux C, Cultrone A, Delorme C, Denariaz G, Dervyn R, Foerstner KU, Friss C, van de Guchte M, Guedon E, Haimet F, Huber W, van Hylckama-Vlieg J, Jamet A, Juste C, Kaci G, Knol J, Kristiansen K, Lakhdari O, Layec S, Le Roux K, Maguin E, Mérieux A, Melo Minardi R, M'Rini C, Muller J, Oozeer R, Parkhill J, Renault P, Rescigno M, Sanchez N, Sunagawa S, Torrejon A, Turner K, Vandemeulebrouck G, Varela E, Winogradsky Y, Zeller G, Weissenbach J, Ehrlich SD, Bork P, Meta HITC (2011) Enterotypes of the human gut microbiome. Nature 473:174-180. doi:10.1038/nature09944

32. Gu W, Lu Y, Tan Z, Xu P, Xie K, Li X, Sun L (2017) Fungi diversity from different depths and times in chicken manure waste static aerobic composting. Bioresour Technol 239:447-453. doi:https://doi.org/10.1016/j.biortech.2017.04.047

33. Phandanouvong-Lozano V, Sun W, Sanders JM, Hay AG (2018) Biochar does not attenuate triclosan's impact on soil bacterial communities. Chemosphere 213:215-225. doi:https://doi.org/10.1016/j.chemosphere.2018.08.132

34. Chen C-H, Lin Y-L, Chen K-H, Chen W-P, Chen Z-F, Kuo H-Y, Hung H-F, Tang CY, Liou M-L (2017) Bacterial diversity among four healthcare-associated institutes in Taiwan. Sci Rep 7:8230. doi:10.1038/s41598-017-08679-3

35. Matcher GF, Froneman PW, Meiklejohn I, Dorrington RA (2018) Distinct responses of bacterial communities to agricultural and urban impacts in temperate southern African estuaries. Estuar Coast Shelf Sci 200:224-233. doi:https://doi.org/10.1016/j.ecss.2017.11.015

36. Yang Y, Li S, Gao Y, Chen Y, Zhan A (2019) Environment-driven geographical distribution of bacterial communities and identification of indicator taxa in Songhua River. Ecol Indic 101:62-70. doi:https://doi.org/10.1016/j.ecolind.2018.12.047

37. Niu A, Song L-Y, Xiong Y-H, Lu C-J, Junaid M, Pei D-S (2019) Impact of water quality on the microbial diversity in the surface water along the Three Gorge Reservoir (TGR), China. Ecotoxicol Environ Saf 181:412-418. doi:https://doi.org/10.1016/j.ecoenv.2019.06.023

38. Sharmin F, Wakelin S, Huygens F, Hargreaves M (2013) Firmicutes dominate the bacterial taxa within sugar-cane processing plants. Sci Rep 3:3107. doi:10.1038/srep03107

39. Antwi P, Li J, Opoku Boadi P, Meng J, Shi E, Xue C, Zhang Y, Ayivi F (2017) Functional bacterial and archaeal diversity revealed by $16 \mathrm{~S}$ rRNA gene pyrosequencing during potato starch processing wastewater treatment in an UASB. Bioresour Technol 235:348-357.

doi:https://doi.org/10.1016/j.biortech.2017.03.141

40. Gharechahi J, Vahidi MF, Bahram M, Han J-L, Ding X-Z, Salekdeh GH (2021) Metagenomic analysis reveals a dynamic microbiome with diversified adaptive functions to utilize high lignocellulosic forages in the cattle rumen. The ISME J 15:1108-1120. doi:10.1038/s41396-020-00837-2

41. Murphy CL, Biggerstaff J, Eichhorn A, Ewing E, Shahan R, Soriano D, Stewart S, VanMol K, Walker R, Walters P, Elshahed MS, Youssef NH (2021) Genomic characterization of three novel Desulfobacterota classes expand the metabolic and phylogenetic diversity of the Phylum. Environ Microbiol. doi:10.1111/1462-2920.15614 
42. Echenique-Subiabre I, Zancarini A, Heath MW, Wood SA, Quiblier C, Humbert J-F (2018) Multiple processes acting from local to large geographical scales shape bacterial communities associated with Phormidium (cyanobacteria) biofilms in French and New Zealand rivers. Sci Rep 8:14416. doi:10.1038/s41598-018-32772-w

43. Majdi N, Uthoff J, Traunspurger W, Laffaille P, Maire A (2020) Effect of water warming on the structure of biofilm-dwelling communities. Ecol Indic 117:106622. doi:https://doi.org/10.1016/j.ecolind.2020.106622

44. Mayr MJ, Besemer K, Sieczko A, Demeter K, Peduzzi P (2020) Bacterial community composition and function along spatiotemporal connectivity gradients in the Danube floodplain (Vienna, Austria). Aquat Sci 82:28. doi:10.1007/s00027-020-0700-x

45. Jones SE, Newton RJ, McMahon KD (2009) Evidence for structuring of bacterial community composition by organic carbon source in temperate lakes. Environ Microbiol 11:2463-2472. doi:https://doi.org/10.1111/j.1462-2920.2009.01977.x

46. Liu Y, Yao T, Jiao N, Zhu L, Hu A, Liu X, Gao J, Chen Z-Q (2013) Salinity Impact on Bacterial Community Composition in Five High-Altitude Lakes from the Tibetan Plateau, Western China. Geomicrobiol J 30:462-469. doi:10.1080/01490451.2012.710709

47. Li H, Chi Z, Li J, Wu H, Yan B (2019) Bacterial community structure and function in soils from tidal freshwater wetlands in a Chinese delta: Potential impacts of salinity and nutrient. Sci Total Environ 696:134029. doi:https://doi.org/10.1016/j.scitotenv.2019.134029

48. Yimit H, Eziz M, Mamat M, Tohti G (2011) Variations in groundwater levels and salinity in the lli River Irrigation Area, Xinjiang, northwest China: a geostatistical approach. Int J Sustain Dev World Ecol 18:55-64. doi:10.1080/13504509.2011.544871

49. Xu L, Du H, Zhang X (2019) Spatial distribution characteristics of soil salinity and moisture and its influence on agricultural irrigation in the Ili River Valley, China. Sustainability 11:7142

50. Jiao S, Lu Y (2020) Soil pH and temperature regulate assembly processes of abundant and rare bacterial communities in agricultural ecosystems. Environ Microbiol 22:1052-1065. doi:https://doi.org/10.1111/1462-2920.14815

\section{Figures}



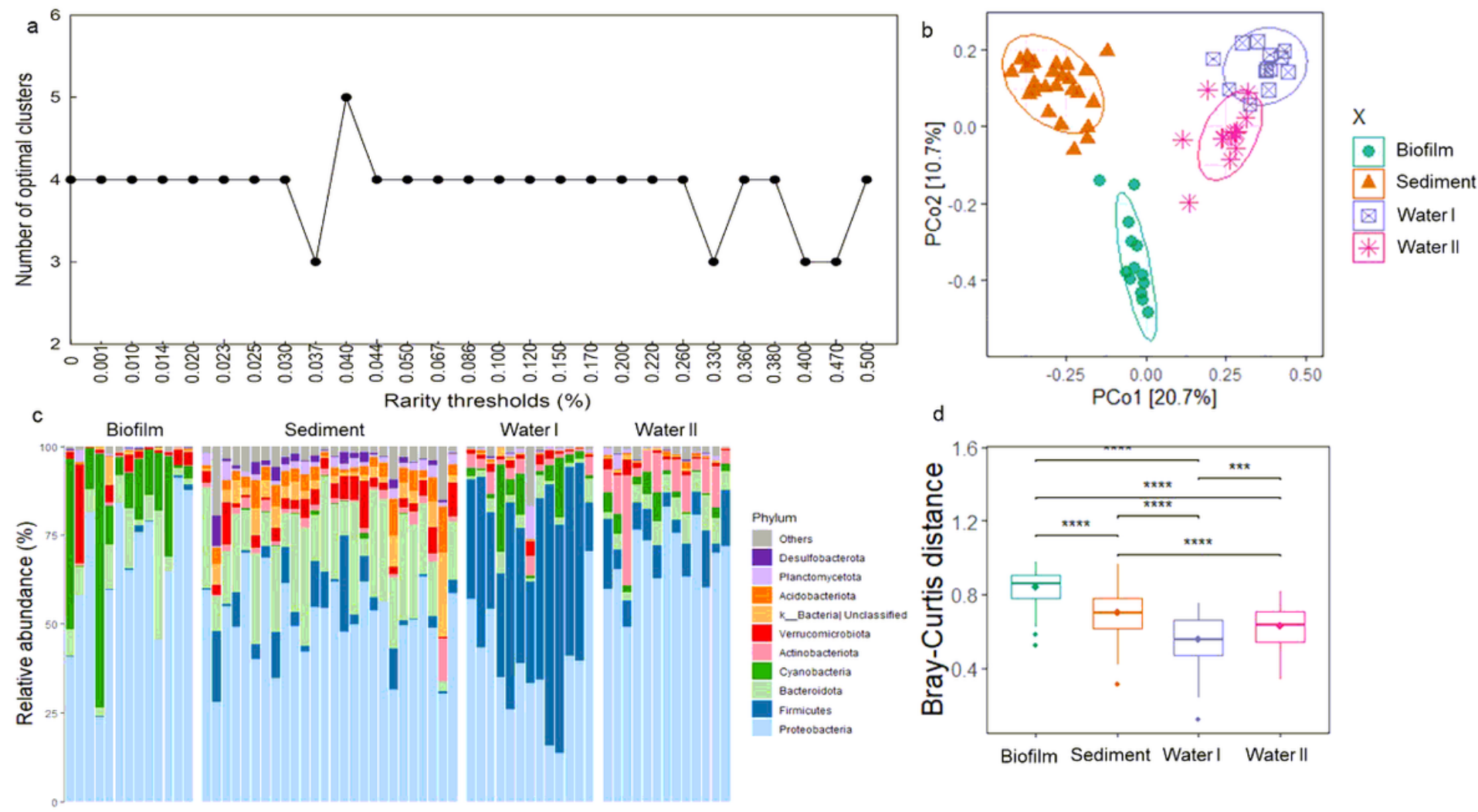

Figure 1

The optimal clusters of bacterial communities in lli river obtained by Dirichlet multinomial mixture (a). The principal coordination analysis (PCoA, b), composition and difference in Bray-Curtis distance of bacterial communities across the four optimal ecotypes. 


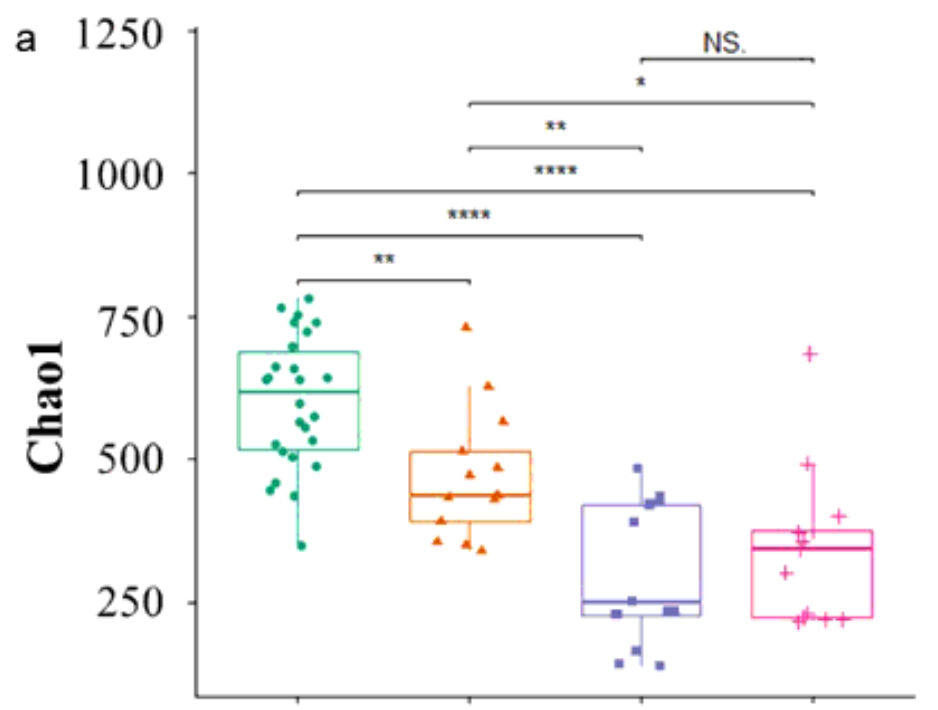

Sediment Water II Biofilm Water I

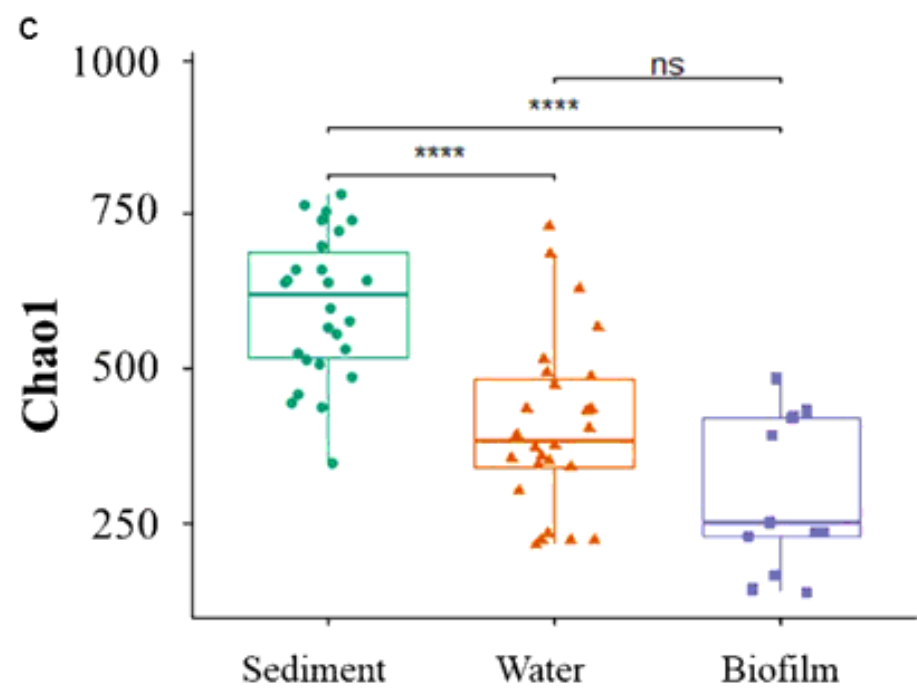

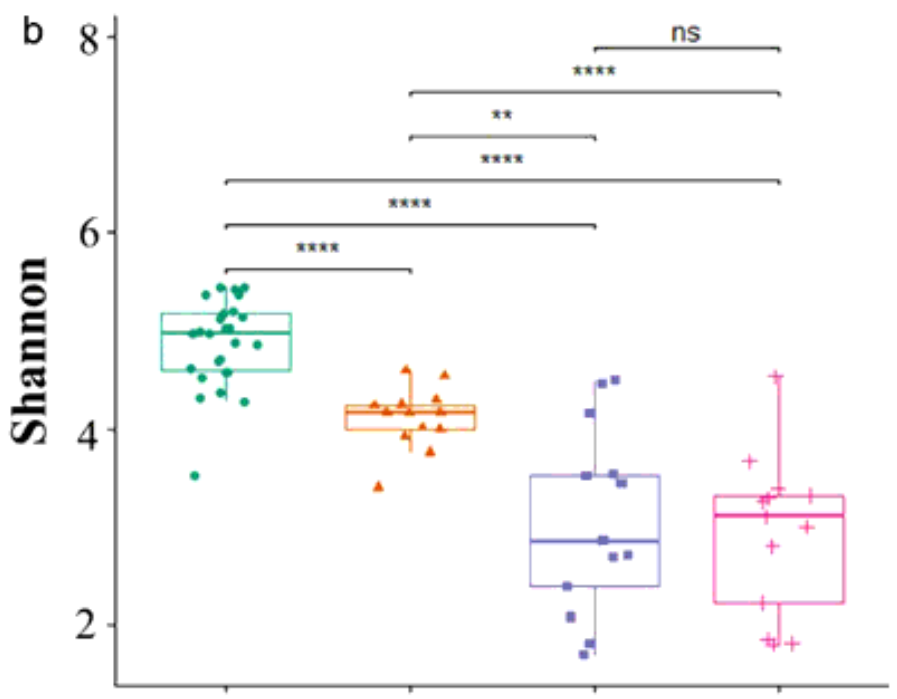

Sediment Water II Biofilm Water I

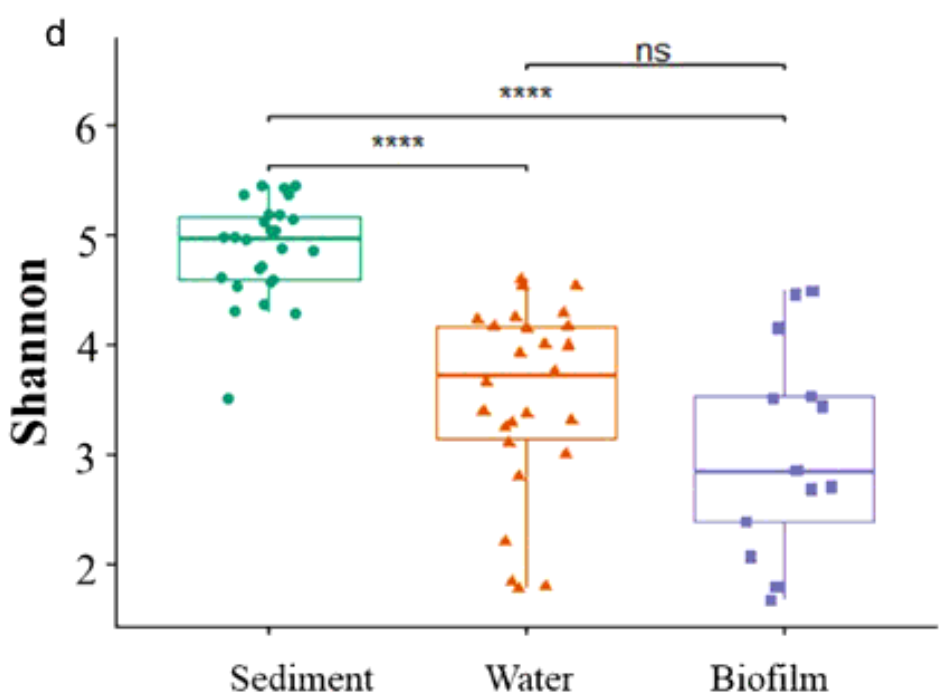

Figure 2

The comparison and difference in the Chao1 $(a, c)$ and Shannon $(b, d)$ of bacterial communities across ecotypes or habitats. 


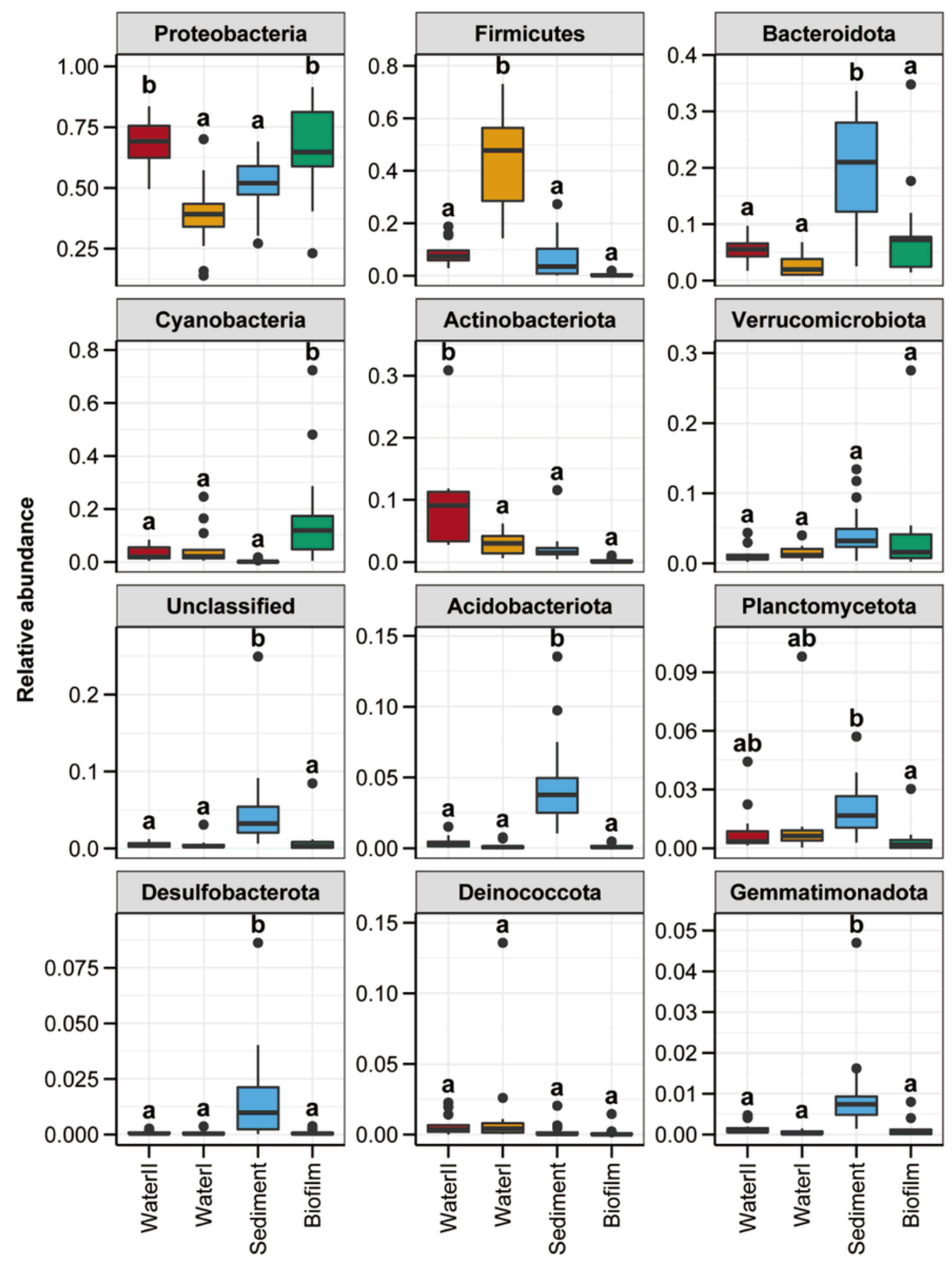

Figure 3

Difference in the relative abundance of top 12 phyla across the four ecotypes 

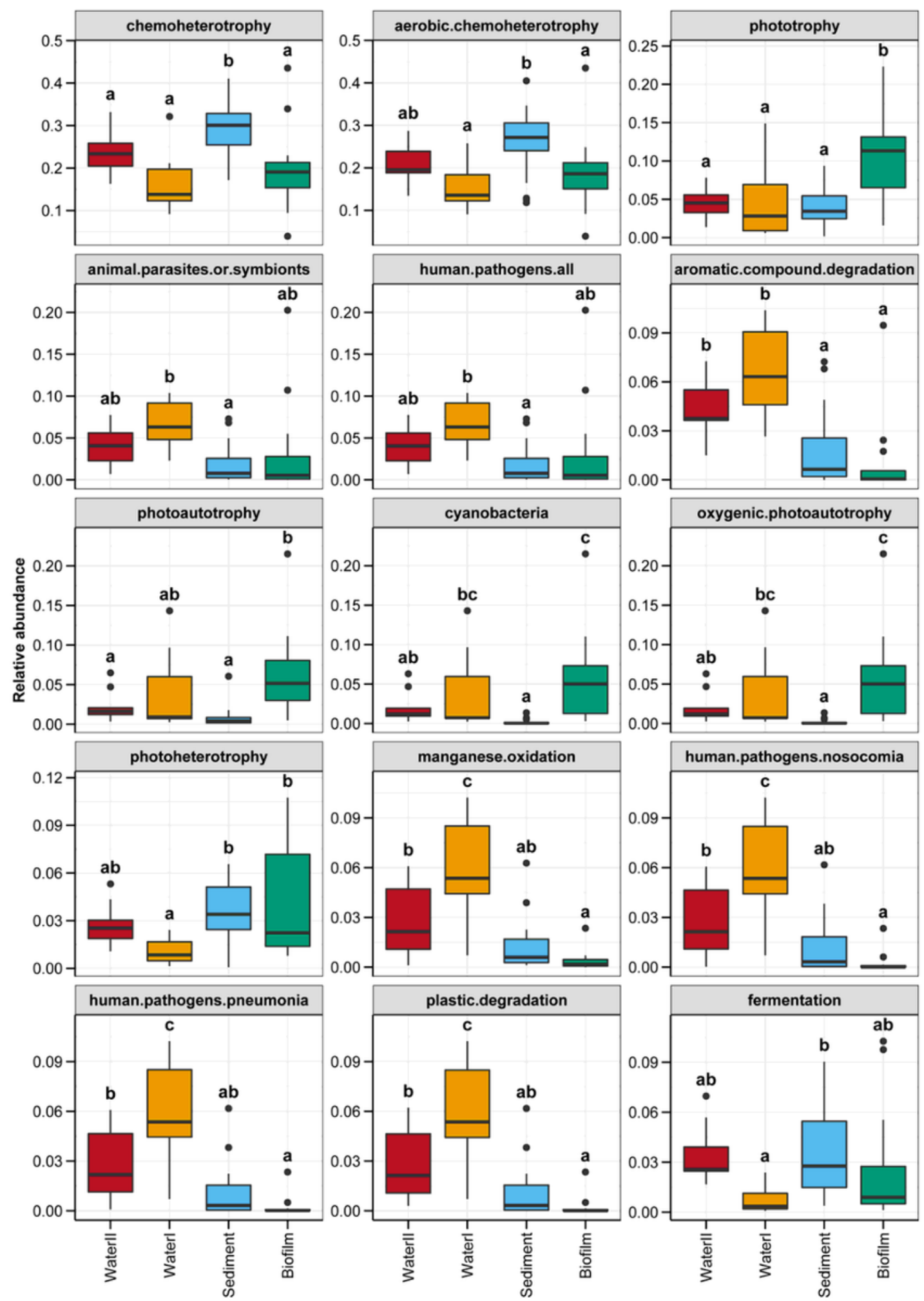

Figure 4

Difference in the relative abundance of top 15 predicated bacterial community functions across the four ecotypes 

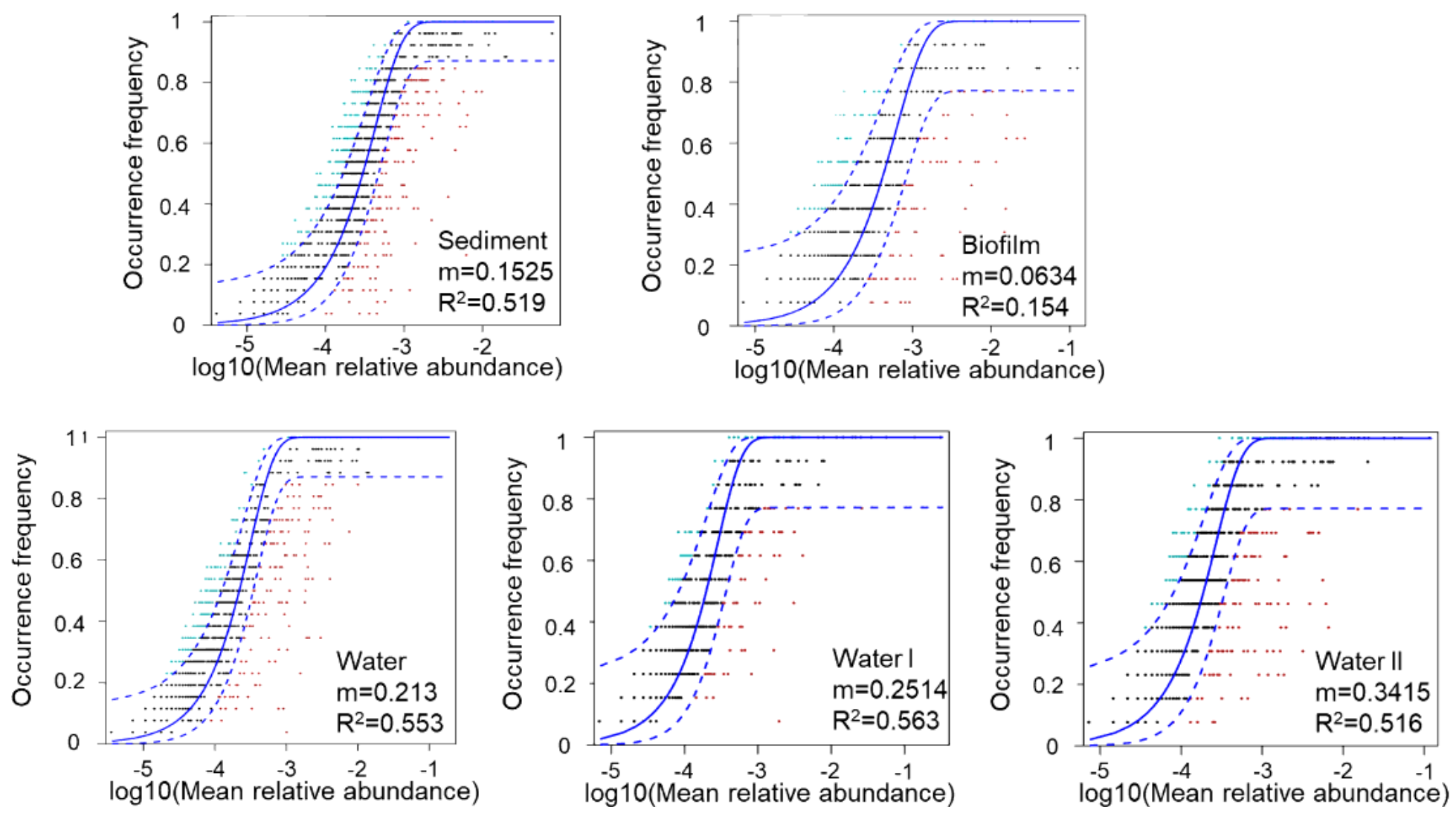

Figure 5

Fit of bacterial communities at each site to the NCM across different habitats or ecotypes.
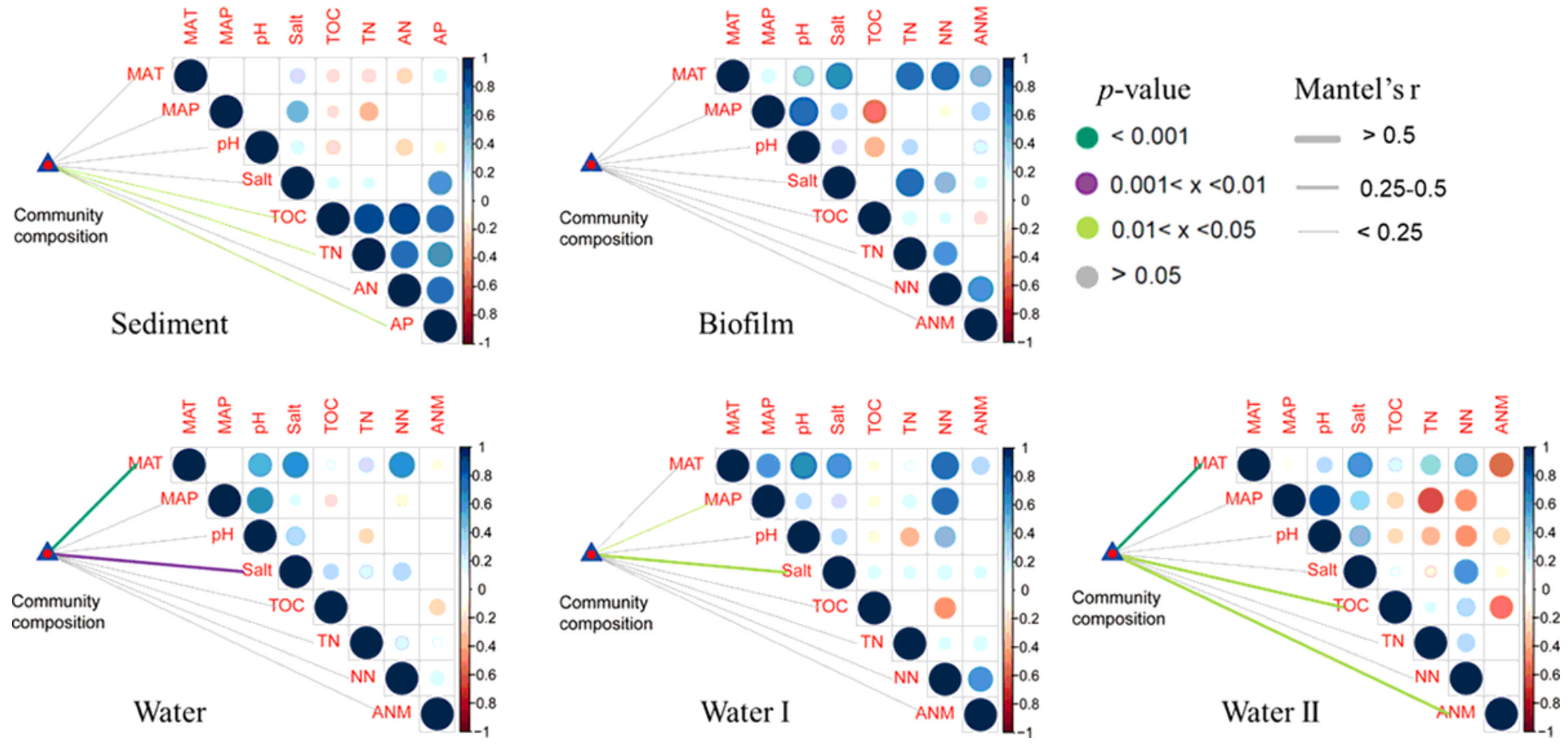

Figure 6

The correlations between environmental factors and the taxonomic and functional compositions of bacterial communities in the lli River via Mantel's test. The width and color of the lines indicated the 
magnitudes and significance of the test.

\section{Supplementary Files}

This is a list of supplementary files associated with this preprint. Click to download.

- DistinctbacterialassemblyMEsupplementaryinformation.docx 